\title{
Cell Discovery: A new publishing experience
}

\author{
Cell Discovery (2015) 1, 15009; doi:10.1038/celldisc.2015.9; published online 28 April 2015
}

It is my great pleasure to write this Editorial to announce the birth of Cell Discovery, a newly launched, fully open access (OA) international journal covering all areas of molecular and cell biology. The journal is co-sponsored by Shanghai Institutes for Biological Sciences (SIBS, and more specifically, by Institute of Biochemistry and Cell Biology, and Shanghai Information Center for Life Sciences, two daughter institutions of SIBS) of the Chinese Academy of Sciences (CAS), and the Chinese Society for Cell Biology, and is jointly published with Nature Publishing Group.

Cell Discovery (http://www.nature. com/celldisc/) will publish results of significance and originality in all areas of molecular and cell biology, including (but not limited to) cell growth and differentiation, signal transduction, apoptosis, chromatin modulation, epigenetics, transcriptional regulation, stem cell research, development, immunology, neurosciences, and plant cell biology. The editorial team of Cell Discovery is led by Professors Gang Pei and Dangsheng $\mathrm{Li}$ (the Editor and Executive Editor of the journal), who also head the renowned international journal Cell Research (http:// www.nature.com/cr/index.html). An outstanding international Editorial Board (http://www.nature.com/cell disc/about/editors) will be working with the editorial team of Cell Discovery and with NPG to develop the journal into a highly visible platform and place of choice for scientists all around the world to publish their high-quality works.

Several unique features will clearly distinguish Cell Discovery from other journals, including other OA journals. First, it is launched and operated as a sister journal of Cell Research, a highly prominent international journal with a current impact factor of 11.981. Indeed, Cell Research has made great strides in recent years towards its goal of becoming a high-profile platform for scientists to publish their outstanding research results. A competent and dedicated professional team of Scientific Editors, who take great pride in providing the best possible service to our authors, and the tremendous support from the broad scientific community have been two keys to the success of Cell Research. As the sister journal of Cell Research, Cell Discovery is perfectly positioned to inherit all these key 'genetic factors' that have contributed to the ongoing success of its elder sister, which will be instrumental in shaping its own development in the future.

Second, we are determined to establish Cell Discovery as a highquality OA journal. In other words, it will not be 'just another OA journal' in the street. A major part of our motivation in launching Cell Discovery is to better serve the scientific community, and we firmly believe that this goal is best achieved by establishing a high-quality OA journal. In recent years, as Cell Research is entering a new stage of competing with some of the best journals in the field, its bar for acceptance is also getting higher: generally, publishing in Cell Research would require the study to be of unusual significance and broad conceptual advance. The high selectivity of Cell Research has dictated that it is only able to publish a very small portion of the received papers; many of the papers declined by Cell Research actually represent solid studies that could well be published in prestigious society journals. By establishing Cell Discovery, we hope to better serve our authors by providing an attractive alternative venue for publication when their papers are deemed to fall just a bit short of the stringent bar of Cell Research. Of course, serving our old customers is only part of the story; the journal's arms are also wide open to welcome submissions from other scientists all over the world. To ensure high quality, Cell Discovery will be implementing a basic acceptance bar that, at a minimum, is comparable to prestigious society journals in the respective field of the work.

Third, we will strive to make publishing fun for our authors. Scientific research requires arduous efforts, but for those who love science, it also means a lot of fun. However, the word fun can be hardly used to describe the publishing process, especially at top journals (for example, see http://www.nature. com/news/2011/110427/full/472391a. $\mathrm{html})$. More than often, the publishing of a study can be delayed for months due to the demands for extra 
lab works by the review process. Peer review has a critical role in the quality control process of scientific publishing, and in most cases it also helps to improve the papers that are eventually published. Nevertheless, endless demands of unnecessary experiments that do little to improve the paper can be very frustrating to the authors, causing not only delays to the publication of the paper, but also the wasting of precious time and resources that could otherwise be directed to further the research. Altogether, this may hinder the progress of science. At Cell Discovery, we will take specific measures to avoid the situation of demanding for unnecessary experiments and the consequent unnecessary delays in the publication process. Our knowledgeable Scientific Editors will work closely with the authors and referees to streamline the peer review and revision process, and to help the authors identify 'necessary' experiments. In short, we will make all efforts to make the experience of publishing at Cell Discovery an enjoyable one
Accompanying this grand launch are four excellent original papers, spanning the fields of apoptosis, synthetic biology and biotechnology, plant molecular biology, and epigenetics. Xuejun Zhang and colleagues from the SIBS report the discovery of a novel DNase that acts to cleave chromosomal DNA during mammalian cell apoptosis. Jindong Zhao and colleagues from Peking University report the successful creation of an engineered cyanobacterium that efficiently produces cellulose from sunlight and $\mathrm{CO}_{2}$, a result with important implications for biofuel production. Xiaofeng $\mathrm{Cao}$ and colleagues from Institute of Genetics and Developmental Biology of CAS report the molecular mechanism by which a plant histone demethylase controlling RNAmediated gene silencing and flowering time is recruited to its chromatin targets. Robert Liefke and Yang Shi from Harvard University report the discovery of a novel regulator of chromatin modifications at $\mathrm{CpG}$ islands. I believe this first group of published papers nicely illustrates two important characteristics of Cell
Discovery: broad scope and high quality.

Please join us to congratulate the birth of Cell Discovery. I would also like to extend our warmest invitations to scientists all over the world to submit their exciting works to the journal. Let us work together to make publishing fun, something it should be.

Dangsheng $\mathrm{Li}^{1}$

${ }^{I}$ Shanghai Institutes for Biological Sciences, Chinese Academy of Sciences, Shanghai 200031, China; Deputy Editor-in-Chief, Cell Research Executive Editor, Cell Discovery, dsli@sibs.ac.cn

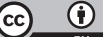

This work is licensed under a Creative Commons Attribution 4.0 International License. The images or other third party material in this article are included in the article's Creative Commons license, unless indicated otherwise in the credit line; if the material is not included under the Creative Commons license, users will need to obtain permission from the license holder to reproduce the material. To view a copy of this license, visit http://creativecommons.org/licenses/ by $/ 4.0 /$ 